\section{Australian Journal of \\ Crop Science}

AJCS 12(08):1304-1312 (2018)

doi: 10.21475/ajcs.18.12.08.PNE1108

\title{
Genotype-by-environment interaction analysis of maize hybrids for grain yield and maize streak virus severity in the mid-altitude agro-ecologies
}

\author{
Lameck M. Nyaligwa ${ }^{1}$, Hussein Shimelis ${ }^{1}$, Learnmore Mwadzingeni ${ }^{1,2^{*}}$, Mark D. Laing ${ }^{1}$ \\ ${ }^{1}$ University of KwaZulu-Natal, School of Agricultural, Earth and Environmental Sciences, Private \\ Bag X01, Scottsville 3209, Pietermaritzburg, South Africa \\ ${ }^{2}$ Selian Agricultural Research Institute (SARI), P.O. Box 6024 Arusha, Tanzania
}

\section{*Corresponding author: mwadzingenil@ukzn.ac.za}

\begin{abstract}
The objective of this study was to determine the magnitude of $G \times E$, and to select promising experimental maize hybrids with high grain yield and MSV resistance. Fifty genotypes comprising of 45 newly developed single cross hybrids and five standard checks were evaluated using a $5 \times 10$ alpha lattice design with two replications across six environments. The Additive Main Effects and Multiplicative Interaction (AMMI) and the Genotype and Genotype by Environment (GGE) biplot models were used to quantify $\mathrm{G} \times$ $\mathrm{E}$ interaction. AMMI analysis revealed that genotype, $\mathrm{G} \times \mathrm{E}$ and environmental effects contributed to $12.4 \%, 17.76 \%$ and $52.06 \%$ of the variation in yield, respectively. Experimental hybrid G43 (CML509/CML390) had a relatively high mean grain yield of $6.70 \mathrm{t} \mathrm{ha}^{-1}$ and moderate MSV severity of $31.88 \%$ across the six testing environments. This hybrid can be recommended for direct production, or for three-way hybrid development. Hybrids with low MSV severity scores but exhibiting low grain yields could be useful genetic resources for MSV resistance breeding in maize.
\end{abstract}

Keywords AMMI analysis, genotype by environment interaction, GGE biplot, maize streak virus, mid-altitude tropics.

Abbreviations: AMMI_Main Effects and Multiplicative Interaction; ASV_AMMI stability values; $G \times$ E_genotype by environment interaction; GGE_Genotype and Genotype by Environment; MSV_maize streak virus; YLD_Grain yield.

Introduction

Maize (Zea mays L., $2 \mathrm{n}=2 \mathrm{x}=20$ ) is an important cereal crop grown for food and animal feed globally. It is a staple food in most sub-Saharan countries including Tanzania, where it is grown on about $45 \%$ of the total cultivated land (BarreiroHurle 2012). The crop supports approximately 45 million people in Tanzania and contributes to $50 \%$ of the cash income of rural communities (Barreiro-Hurle 2012; Mrutu et al., 2014). However, maize growers, including commercial farmers, often achieve low and variable yields due to damage caused by the maize streak virus (MSV) disease (Barreiro-Hurle 2012; Adu et al., 2013; Mrutu et al., 2014). MSV is estimated to cause yield losses of 70 to $100 \%$ in fields subjected to high infection levels, occurring early in the crop's life (Bosque-Perez et al., 1998; Alegbejo et al., 2002). Therefore, there is a need to develop stable hybrids in terms of yield performance and MSV resistance.

Genotype by environment interaction is a function of the interaction effects of the genotypes and test environments (Rashidi et al., 2013). Genotype evaluation and recommendation for production in a particular environment is often complex due to the confounding effects of $G \times E$, especially under conditions of biotic and abiotic stress (Comstock and Moll 1963). When environmental conditions are divergent, crossover $\mathrm{G} \times \mathrm{E}$ interaction or rank changes occur, further complicating genotype evaluation (Yan and Tinker 2006; Rashidi et al., 2013; Badu-Apraku et al., 2014). Test sites that are highly discriminating and representative of the growing environments provide superior assessments, enabling assignment of cultivars to appropriate production environments (Nyoka et al., 2012; Trouche et al., 2014). Therefore, evaluation of newly developed varieties across several environments (sites and seasons) is fundamental to estimate the magnitude of $G \times E$, and for cultivar recommendation with broader or narrow adaptation, and yield stability (Abakemal et al., 2016).

The magnitude of $G \times E$ is estimated using different stability models. The Additive Main Effects and Multiplicative Interaction (AMMI) and the Genotype Main Effect and Genotype by Environment interaction effects (GGE) are the most widely used models (Dehghani et al., 2009; Oliveira et al., 2010; Munawar et al., 2013). These models capture G x E interaction sum of squares, and separate the main and interaction effects (Kota et al., 2013; Rad et al., 2013; Rashidi et al., 2013). The AMMI and GGE biplot analyses delineate mega-environments, and identify high yielding and better adapted genotypes (Balestre et al., 2009; Oliveira et al., 2010). GGE biplot analysis is based on environment centered principal component analysis (PCA) and provides a complete 
visual evaluation of the data through graphical representation of mean performance and stability of genotypes (Yan et al., 2007). It also displays the "which won where pattern" of the data that identifies genotypes with the best performance in each growing environment or mega-environment (Rad et al., 2013). AMMI analysis uses double centered principal component analysis (PCA) (Harismendy et al., 2009; Farshadfar et al., 2013).

Breeding stable, high yielding and disease resistant maize cultivars is the most economic and sustainable option to attain potential production and productivity (Badu-Apraku et al., 2012). Several single cross hybrids have been recently developed in an effort to improve maize productivity under MSV prone environments in Tanzania. The experimental hybrids should be assessed under target production environments of the mid-altitude agro-ecologies of the country to select most stable and superior hybrids with high yield potential and MSV resistance. In this agro-ecology, there has been no previous study that evaluated and reported on newly developed maize hybrids for grain yield and MSV resistance. In light of this, the objective of this study was to determine the magnitude of $\mathrm{G} \times \mathrm{E}$, and to select promising experimental maize hybrids that are adapted to the mid-altitude agro-ecologies, with high grain yield and MSV resistance.

\section{Results}

\section{Combined analysis of variance for grain yield and MSV severity}

Combined analysis of variance for grain yield and MSV severity showed high significant $(P<0.001)$ differences due to genotype, environments and $G \times E$ interaction effects (Table 1). This indicated the existence of marked variability among the set of experimental hybrids evaluated and the test environments. However, environmental effects had low but significant $(P<0.05)$ effects on reaction to MSV. Among the main effects, the environment accounted for the largest proportion $(97.02 \%)$ of the observed variation in grain yield followed by the genotypes (2.33\%) and G X E (0.65\%), respectively. For MSV reactions, variation was mostly due to the effects of genotypes (48.35) followed by the environment (40.68), while their interaction made the smallest contribution (11.36\%). These results allowed for further $\mathrm{G} \times \mathrm{E}$ analysis.

\section{AMMI analysis of variance for grain yield and MSV severity}

AMMI analysis revealed highly significant differences $(P<$ 0.001 ) for grain yield and MSV severity due to genotype and environment effects (Table 2). The first and second interaction principal components (IPCA 1 and 2) were significant $(P \leq .05)$ for the studied traits, explaining $67.70 \%$ and $60.43 \%$ of the total variation in grain yield and MSV severity, respectively. The first principal component explained $40.97 \%$ and $37.79 \%$ of the total variation in grain yield and MSV reaction, while the second component explained $26.73 \%$ and $22.64 \%$ of the observed variation, in that order (Table 2). Genotype and G x E interaction effects attributed to the total genetic variation of $12.4 \%$ and $17.76 \%$ for grain yield and $42.52 \%$ and $28.35 \%$ for MSV severity, respectively. Environmental effect explained $52.06 \%$ and
$2.77 \%$ of the total variation of grain yield and MSV severity, respectively.

\section{Mean grain yield performance and AMMI stability value}

The mean yield response of the 50 genotypes that were evaluated across six environments (E1 to E6) are presented in Supplementary Table 1 . The same hybrid performed consistently well in E2, E3, and E6; with mean yields of 8.62, 7.37 and $7.54 \mathrm{t} \mathrm{ha}^{-1}$, respectively. The AMMI stability values ranged from -3.71 to 2.59 displayed by G6 and G45, respectively (Supplementary Table 1 ). Other hybrids with significant negative ASVs were G3, G11, G26 and G50; while those with significant positive values included G28 and G37. Hybrids G12, G18, G19, G35 and G41 had relatively low ASV values of $0.16,0.07,0.04,0.13$ and 0.12 , respectively. Another better performing genotype was G43, which ranked second in yield performance across all environments with a mean yield and ASV value of $6.70 \mathrm{t} \mathrm{ha}^{-1}$ and 0.79 , respectively. $\mathrm{G} 28$ ranked the highest, providing a mean yield of $8.62 \mathrm{t} \mathrm{ha}^{-1}$ in E3 and attained second and third positions in E5 $\left(6.84 \mathrm{t} \mathrm{ha}^{-1}\right)$ and E1 $\left(9.91 \mathrm{t} \mathrm{ha}^{-1}\right)$. Likewise, G15 displayed high grain yields of 8.44 and $6.92 \mathrm{t} \mathrm{ha}^{-1}$ under E2 and E3, respectively, and was consistently ranked second in these environments (Supplementary Table 1). At the Ngaramtoni site, G10 was selected as the best hybrid, consistently expressing the highest yield over the two growing seasons, while G43 was selected as the best yielder in Igomelo. More than $40 \%$ of the tested hybrids, including G28 and G43, performed above average and were adapted to high yielding environments. The Ngaramtoni test conditions (E1 and E2) were considered to be high yielding environments, while Krishna and Igomelo were designated as lower yielding environments. Ngaramtoni had consistently above average yield, with the highest environmental mean yields of $7.90 \mathrm{t}$ $\mathrm{ha}^{-1}$ and $6.82 \mathrm{t} \mathrm{ha}^{-1}$ in the first and second season, respectively (Supplementary Table 1 ).

\section{GGE biplot analysis}

The GGE biplot (Fig. 1) accounted for $67.7 \%$ of the total observed variation, and identified environments E1 and E2 as being highly discriminating and closely related, based on their long vectors with an acute angle between them. These environments had negative relationships with the other four environments. E3 and E5 were also moderately discriminative, while E6 had the least discriminating capacity, as indicated by its having the shortest vector. Ranking of environments based on the most ideal test environments revealed E1 as the most representative, followed by E2 (Fig. 2). In contrast, E3, E4, E5 and E6 were less representative. Further, the average-environment coordination view, showing the ranking of hybrids relative to an ideal hybrid, identified hybrids G1, G12 and G13 among the best genotypes with yield performances above average (Fig. 3). The "which won where" view of the GGE biplot for grain yield (Fig. 4) accounted for $65.72 \%$ of the total variation. The first and second principal components contributed $44.69 \%$ and $21.03 \%$ of the observed variation in grain yield explained by this biplot, respectively. Hybrids G43 and G10 won in the mega-environments, including E3, E4, E5 
Table 1. Combined analysis of variance for grain yield and MSV reaction of 45 experimental maize hybrids and five standard checks evaluated across six environments in Tanzania.

\begin{tabular}{|c|c|c|c|}
\hline & & GYD & MSV \\
\hline Source of variation & DF & MS & MS \\
\hline Genotype (G) & 49 & $9.92^{* * *}$ & $5057.227^{* * *}$ \\
\hline Environment (E) & 5 & $411.92^{* * *}$ & $1651.686^{*}$ \\
\hline Replication/E & 1 & $0.00^{\mathrm{ns}}$ & $1187.789^{\mathrm{ns}}$ \\
\hline$G \times E$ & 245 & $2.77^{* * *}$ & $1147.412^{* * *}$ \\
\hline Block & 18 & $0.87^{\mathrm{ns}}$ & $702.0206^{\mathrm{ns}}$ \\
\hline Error & 281 & 0.97 & 714.0129 \\
\hline Total & 599 & 426.46 & 10460.2 \\
\hline
\end{tabular}

$\mathrm{DF}=$ degrees of freedom, $\mathrm{G} \times \mathrm{E}=$ genotype by environment interaction; $\mathrm{GYD}=$ grain yield $\left(\mathrm{t} \mathrm{ha} \mathrm{a}^{-1}\right), \mathrm{MSV}=$ Maize streak virus disease severity scores $(\%), \mathrm{MS}=\mathrm{mean} \mathrm{squares}$.

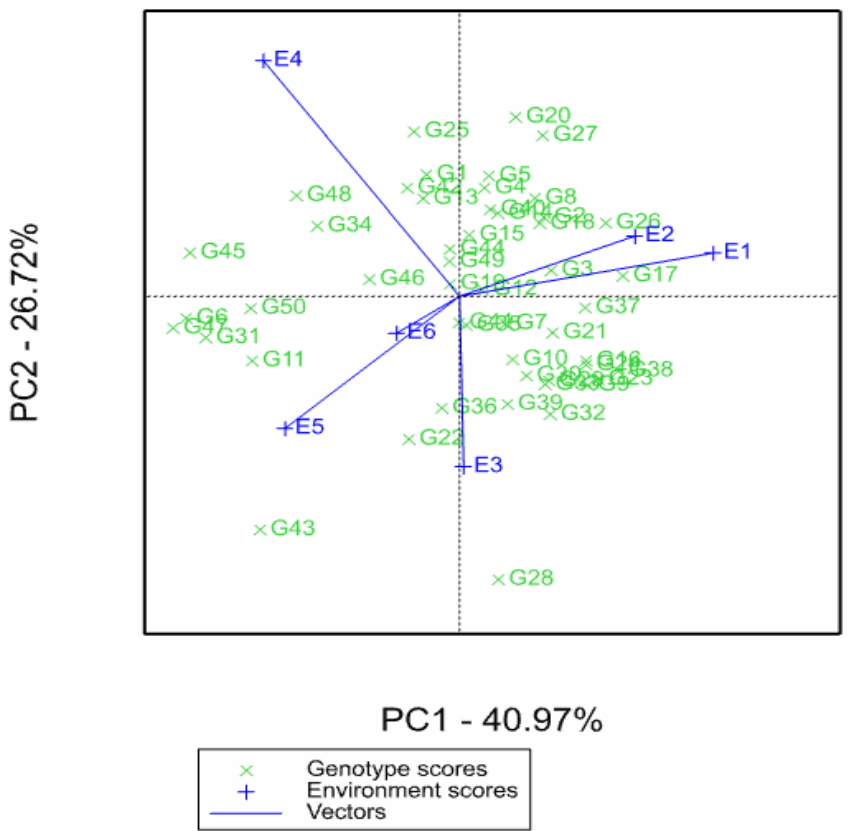

Fig 1. Environment-vector view showing similarities among test environments in discriminating the hybrids. E1 (Ngaramtoni 2012/13), E2 (Ngaramtoni 2013/14), E3 (Krishna 2012/13), E4 (Krishna 2013/14), E5 (Igomelo 2012/13) and E6 (Igomelo 2013/14), dotted vertical and horizontal lines indicate points where PC1 and PC2 axis had a value of zero, respectively. See codes of genotypes (G1 to G50) in Supplementary Table 3.

Table 2. AMMI analysis of variance for grain yield and MSV severity of 45 maize hybrids and five standard checks tested across six environments in Tanzania.

\begin{tabular}{|c|c|c|c|c|c|c|c|}
\hline \multirow[b]{2}{*}{ Source of variation } & \multirow[b]{2}{*}{ DF } & \multicolumn{3}{|c|}{ GYD } & \multicolumn{3}{|c|}{ MSV } \\
\hline & & MS & $\%$ TSS & $\% G E$ & MS & \%TSS & \%GE \\
\hline Genotypes (G) & 49 & $5.08 * * *$ & 12.4 & & $2023.6^{* * *}$ & 42.52 & \\
\hline Environments (E) & 5 & $208.77^{* * *}$ & 52.06 & & $365.8 \mathrm{~ns}$ & 2.77 & \\
\hline $\mathrm{G} \times \mathrm{E}$ & 245 & 1.45 & 17.76 & & 269.8 & 28.35 & \\
\hline IPCA 1 & 53 & $2.75^{* * *}$ & & 40.97 & $471.4^{* * *}$ & & 37.79 \\
\hline IPCA 2 & 51 & $1.87^{* * *}$ & & 26.73 & $293.5^{*}$ & & 22.64 \\
\hline Residuals & 141 & 0.82 & & & 185.5 & & \\
\hline Total & 543 & 220.74 & & & 3609.6 & & \\
\hline
\end{tabular}

$\mathrm{DF}=$ degree of freedom, $\mathrm{G} \times \mathrm{E}=$ genotype by environment interaction, $\mathrm{SS}=$ sum of squares, $\% \mathrm{TSS}=$ percent total sum of squares, MS = mean squares; GYD = grain yield $(\mathrm{t}$ ha $\left.^{-1}\right), M S V=$ Maize streak virus disease severity (\%). 



Fig 2. GGE biplot showing ranking of test environments relative to an ideal test environment. E1 (Ngaramtoni 2012/13), E2 (Ngaramtoni 2013/14), E3 (Krishna 2012/13), E4 (Krishna 2013/14), E5 (Igomelo 2012/13) and E6 (Igomelo 2013/14), dotted vertical and horizontal lines indicate points where PC1 and PC2 axis had a value of zero, respectively. See codes of genotypes (G1 to G50) in Supplementary Table 3.



PC1 - $44.69 \%$

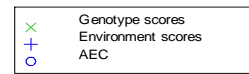

Fig 3. Average-environment coordination (AEC) view showing the ranking of hybrids relative to an ideal genotype. E1 (Ngaramtoni 2012/13), E2 (Ngaramtoni 2013/14), E3 (Krishna 2012/13), E4 (Krishna 2013/14), E5 (Igomelo 2012/13) and E6 (Igomelo 2013/14), dotted vertical and horizontal lines indicate points where PC1 and PC2 axis had a value of zero, respectively. See codes of genotypes (G1 to G50) in Supplementary Table 3.

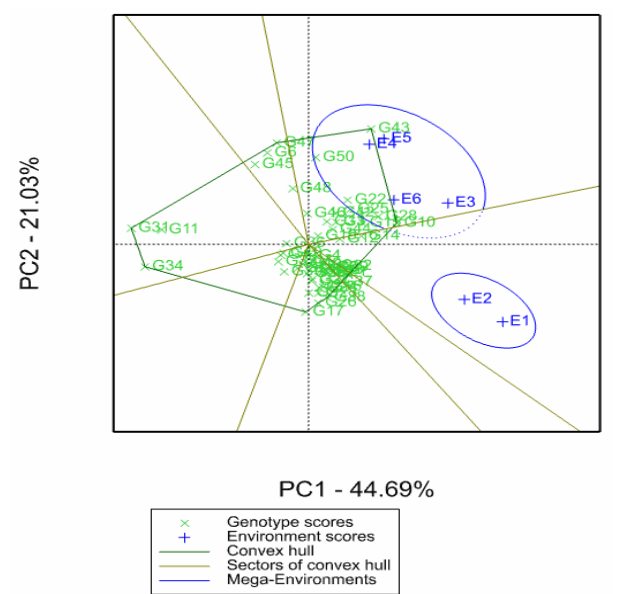

Fig 4. Which-won-where view of the GGE biplot showing best performing hybrid in particular environments. E1 (Ngaramtoni 2012/13), E2 (Ngaramtoni 2013/14), E3 (Krishna 2012/13), E4 (Krishna 2013/14), E5 (Igomelo 2012/13) and E6 (Igomelo 2013/14), dotted vertical and horizontal lines indicate points where PC1 and PC2 axis had a value of zero, respectively. See codes of genotypes (G1 to G50) in Supplementary Table 3. 



Fig 5. Average environment coordination (AEC) view showing mean performance and stability of $45 \mathrm{~F} 1$ hybrids tested across six environments (E1-E6). E1 (Ngaramtoni 2012/13), E2 (Ngaramtoni 2013/14), E3 (Krishna 2012/13), E4 (Krishna 2013/14), E5 (Igomelo 2012/13) and E6 (Igomelo 2013/14), dotted vertical and horizontal lines indicate points where PC1 and PC2 axis had a value of zero, respectively. See codes of genotypes (G1 to G50) in Supplementary Table 3.
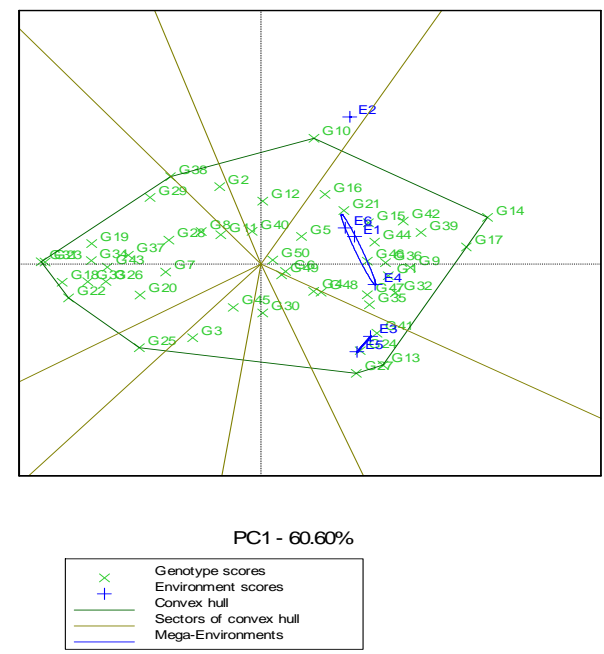

Fig 6. The "which won where" pattern view of GGE biplot, showing the most resistant and susceptible hybrids to MSV disease in particular test environments. E1 (Ngaramtoni 2012/13), E2 (Ngaramtoni 2013/14), E3 (Krishna 2012/13), E4 (Krishna 2013/14), E5 (Igomelo 2012/13) and E6 (Igomelo 2013/14), dotted vertical and horizontal lines indicate points where PC1 and PC2 axis had a value of zero, respectively. See codes of genotypes (G1 to G50) in Supplementary Table 3.


Fig 7. GGE biplot view showing ranking of hybrids based on their reaction to MSV disease, and the stability of their severity across environments. E1 (Ngaramtoni 2012/13), E2 (Ngaramtoni 2013/14), E3 (Krishna 2012/13), E4 (Krishna 2013/14), E5 (Igomelo 2012/13) and E6 (Igomelo 2013/14), dotted vertical and horizontal lines indicate points where PC1 and PC2 axis had a value of zero, respectively. See codes of genotypes (G1 to G50) in Supplementary Table 3. 



Fig 8. The GGE biplot view showing ranking of hybrids based on an ideal or reference hybrid. E1 (Ngaramtoni 2012/13), E2 (Ngaramtoni 2013/14), E3 (Krishna 2012/13), E4 (Krishna 2013/14), E5 (Igomelo 2012/13) and E6 (Igomelo 2013/14), dotted vertical and horizontal lines indicate points where PC1 and PC2 axis had a value of zero, respectively. See codes of genotypes (G1 to G50) in Supplementary Table 3.

and E6. The average environment coordination view of the GGE biplot showing stability and mean performance ranking of the hybrids explained $64.19 \%$ of the total variation of grain yield (Fig.5).

\section{MSV disease reaction and stability of maize hybrids}

The mean MSV severity, ASV and IPCA scores of the 45 newly developed hybrids and five standard checks evaluated across six test environments are presented in Supplementary Table 2. About 33.3\% of the test hybrids had substantially low MSV reactions including G31 (21.96\%), G23 (23.49\%) and G18 (25.07\%). Most test hybrids had ASV values ranging between -1 and 1 , suggesting that these genotypes were stable in terms of MSV reactions among the testing locations. The "which won where" biplot (Fig. 6) accounted for $75.52 \%$ of the total genotypic variation for MSV reaction. The biplot indicated that hybrids G31, G23, G22, G25 and G38 were superior and adapted to lower disease environments, while G14, G27 and G10 were susceptible (Fig. 6). Ranking of hybrids based on their reaction to MSV and stability across environments is presented in Fig. 7 , which explained $74.72 \%$ of the total variation. Hybrids G20, G7, G3, G22 and G25 expressed low MSV severity and greater stability. The GGE biplot showing ranking of the hybrids based on ideal hybrid (Fig. 8) captured $75.52 \%$ of the total phenotypic variation and hybrids G23, $\mathrm{G} 18$, and $\mathrm{G} 22$ were among the most resistant to MSV.

\section{Discussion}

\section{AMMI analysis}

$G \times E$ interaction effects can be effectively quantified when multi-environment data reveal significant $\mathrm{G} \times \mathrm{E}$ interaction on the response variable (Abakemal et al., 2016). Significant differences were observed due to genotypes, environments and $G \times E$ (Table 1), signaling the potential to select stable, high yielding and MSV resistant hybrids among test genotypes. Gethi et al. (2013) reported that $64.5 \%$ of the total variation is attributed to environmental effects, which is in line with the present findings. Differences in growing temperatures, soil conditions, rainfall distribution and MSV incidences among the three study sites and two growing seasons resulted in differential responses of test genotypes. The magnitude of a $G \times E$ interaction effect is dependent on the genetic variability of any given set of genotypes evaluated. The limited influence of environmental effects on severity of MSV indicates that this trait is influenced by a few major genes whose expression may not be affected by growing conditions (Kyetere et al., 1995; Welz et al., 1998), unlike grain yield whose inheritance is polygenic and shows a complex inheritance pattern (Hallauer et al., 2010).

Genotype-by-environment interaction analysis aids in identification of genotypes with high and stable performance across environments, and in cultivar recommendation for specific growing conditions (Lule et al., 2014). Hybrids G43, G28 and G15 that had high and stable grain yields above $6.5 \mathrm{t} \mathrm{ha}^{-1}$ could be the best candidates for largescale production or three-way hybrid development under a wide range of environmental conditions. Furthermore, hybrids G12, G19, G35, and G41 that had relatively low ASV (high stability) can also be recommended for wide area cultivation, or for breeding. However, these hybrids may need to be tested in other regions with low MSV incidence and severity because they were not superior in terms of resistance to MSV. In contrast, genotypes with narrow adaption showing high grain yield performance in specific environments should be recommended for specific target production areas (Yan et al., 2007). In this case, hybrids G15 can be recommended for cultivation at Ngaramtoni where they produced consistently high yields over the two growing seasons (Supplementary Table 1). Genotype G15 would be ideal for production in areas with low MSV incidences, while G18 can be grown even under high disease pressure (Supplementary Table 2). Relative and differential performance of genotypes guides their designation for production in either high or low yielding 
environments (Kandus et al., 2010; Abuali et al., 2014). Experimental hybrids that performed above average such as G28, G43 and G10 can be recommended for production in high yielding environments such as the Ngaramtoni site.

\section{GGE biplot analysis for yield performance}

The GGE biplot indicates that environments E1 and E2 (Ngaramtoni site) had a greater ability to discriminate between test genotypes for their performances, hence can be used for future screening purposes (Lule et al., 2014). The two environments had negative relationships with the rest, based on the obtuse angles between their vector lines (Fig. 1 ); which could be the cause of crossover interaction observed on the performance of other hybrids. Such causes of rank changes complicate recommendation of cultivars to suitable production areas due to inconsistencies of genotype performance (Yan and Tinker 2006). The concentric circles drawn on the biplot assist breeders to visualize the stability and performance of environments and genotypes. The environments or genotypes falling within or close to the innermost concentric circle are considered ideal (Negash et al., 2013). In this view, environments E1 and E2 were the most effective, with relatively high discriminatory and representative attributes (Fig. 2). These environments should be used in future evaluation of the same set of genotypes because they can distinguish between the genotypes, and also provide a fair representation of other test environments (Yan and Tinker 2006). Conversely, environments E3, E4, E5 and E6 (Krishna and Igomelo) were neither representative nor discriminating, and are therefore undesirable for genotype evaluation (Jandong et al., 2011; Negash et al., 2013). High yielding and stable hybrids such as G4, G14, G46, G25 and G44 can be recommended for wide adaptation. Based on the "which won where" pattern view, according to Yan et al. (2007), hybrids G43 and G10, located at the vertices of the polygon, are considered superior in environments E5 and E6 suggesting that they should be recommended for cultivation in Igomelo only. The existence of different genotypes winning in different environments, which also reflects by rank changes, further confirms strong $\mathrm{G} \times \mathrm{E}$ interaction.

\section{Response of candidate maize hybrids to MSV}

Control of maize streak virus using cultural and chemical control strategies is ineffective, given that the leaf hopper vectors (Cicadulina mbila and C. storeyi) have wide host ranges (Mesfin et al., 1992). Further, chemical control is not useful after the crop is infected. Therefore, growing resistant cultivars is the most viable control option. Stable hybrids with reduced reactions to MSV were G31 (21.96\%), G23 (23.49\%), G18 (25.07\%) and G22 (26.06\%), which were selected for further MSV resistance breeding. These hybrids can be grown in most parts of the mid-altitude agroecologies of Tanzania that experience high MSV incidences (Farshadfar et al., 2013; Mukherjee et al., 2013), while susceptible hybrids such as G4, G5, G10, G16, G27, G28 and G48 should be recommended for cultivation in areas with low incidences of MSV. Low yielding hybrids with stable MSV severity could be used to introduce MSV resistance into high yielding lines and hybrids through production of three-way, or double cross hybrids.

\section{Materials and methods}

\section{Plant materials and study sites}

Fifty genotypes consisting of 45 novel single cross hybrids and standard checks (Supplementary Table 3) were evaluated across three sites during the 2012/13 and 2013/14 growing seasons making six test environments. The test sites included Ngaramtoni ( $3^{0} 18^{\prime} \mathrm{S}, 36^{\circ} 34^{\prime} \mathrm{E}, 1520$ masl) located in the Arusha District and characterized by clay silt loam soils; Krishna $\left(4^{\circ} 22^{\prime} \mathrm{S}, 35^{\circ} 77^{\prime} \mathrm{E}, 1100 \mathrm{masl}\right)$ situated in the Babati District, having clay loam soils, and Igomelo $\left(8^{\circ} 46^{\prime} \mathrm{S}, 34^{\circ} 23^{\prime} \mathrm{E}\right.$, 1118 masl) located in the Mbarali District, with red sandy loam soils. The six environments are designated as follows: E1 (Ngaramtoni 2012/13), E2 (Ngaramtoni 2013/14), E3 (Krishna 2012/13), E4 (Krishna 2013/14), E5 (Igomelo 2012/13) and E6 (Igomelo 2013/14). These sites are hotspot areas for MSV disease, allowing effective germplasm evaluation under natural infection.

\section{Experimental design, data collection and analysis}

The 50 genotypes were planted under rain-fed condition using a $5 \times 10$ alpha lattice design with two replications across the six environments. Each plot consisted of 2 rows of $5.0 \mathrm{~m}$ length with an inter-row and intra-row spacing of 75 $\mathrm{cm}$ and $30 \mathrm{~cm}$, respectively. The crop was fertilized with 150 $\mathrm{kg} \mathrm{ha}^{-1}$ of di-ammonium phosphate during planting followed by top-dressing with an equal amount of calcium ammonium nitrate six weeks after planting. Data on MSV severity was collected as percentage of diseased plants per plot, and severity was measured using a visual scale of 1-5, where $1=$ highly resistant with no symptoms, 2 = resistant with light symptoms, $3=$ moderately resistant with moderate streaking, $4=$ susceptible with severe streaking and $5=$ highly susceptible with severe streaking and stunting (Tefera et al., 2013). Checks UH615 and SC627 were included as comparative controls to assess MSV disease reaction. Grain yield (YLD) per plot was recorded by weighing the total grain harvested per plot at $12.5 \%$ moisture content using a digital scale and later converted to $\mathrm{t} \mathrm{ha}^{-1}$.

The data were checked for normality, independence and homogeneity of variances using the Bartlett's test (Snedecor and Cochran 1989). This was followed by combined analysis of variance (ANOVA) using the standard generalized linear model (GLM) procedure in SAS v9.3 (SAS 2011). AMMI and GGE biplot analyses were performed using the Breeding View statistic utility in the Breeding Management Systems (BMS) software (BMS 2015). AMMI analysis was performed following the AMMI model according to Gauch (2013) and the AMMI stability values (ASV) were calculated from the following formula: $=$ V[(SSIPCA1/SSIPCA2) $($ IPCA2 score $)]^{2}+$

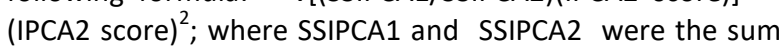
of squares interactions of the first and second PCA, respectively (Lule et al., 2014). GGE biplots were generated using the first two symmetrical scaled principal components, PC1 and PC2, for average tester coordinate (ATC) or average environment coordinate (AEA) views. Vector and polygon view biplots were generated according to Yan and Tinker (2006) using GenStat 14 (Payne 2014). 


\section{Conclusion}

Overall, the new maize hybrids that were evaluated contained sufficient variability for both grain yield and severity to MSV to allow for selection of stable and specifically adapted genotypes. Hybrid G43 had a combination of high mean yield and consistently low reaction to MSV across locations. Therefore, this hybrid can be recommended for production in a wide range of environments, including those with high severity of the disease. Most of the MSV resistant hybrids were poor in yield performances, but will serve as important sources of genes for resistance to MSV that could be exploited through the production of three-way or double cross hybrids.

\section{References}

Abakemal D, Shimelis H, Derera J (2016) Genotype-byenvironment interaction and yield stability of quality protein maize hybrids developed from tropical-highland adapted inbred lines. Euphytica. 209:757-769.

Abuali Al, Abdelmula AA, Khalafalla MM, Hamza NB, Abdalla $A H$, Idris AE (2014) Assessment of yield stability and adaptability of parental inbred lines and F1-hybrids of grain maize (Zea mays L.) using AMMI Analysis. $\mathrm{Br}$ Biotechnol J. 4:339-349.

Adu G, Akromah R, Abdulai M, Obeng-Antwi K, Kena A, Tengan K, Alidu H (2013) Assessment of genotype by environment interactions and grain yield performance of extra-early maize (Zea mays L.) hybrids. J Biol Agric Healthcare. 3:7-15.

Alegbejo M, Olojede S, Kashina B, Abo M (2002) Maize streak mastrevirus in Africa: distribution, transmission, epidemiology, economic significance and management strategies. J Sustain Agric. 19:35-45.

Badu-Apraku B, Oyekunle M, Obeng-Antwi K, Osuman A, Ado S, Coulibay N, Yallou C, Abdulai M, Boakyewaa G, Didjeira A (2012) Performance of extra-early maize cultivars based on GGE biplot and AMMI analysis. J Agric Sci. 150:473-483.

Badu-Apraku B, Akinwale RO, Oyekunle M (2014) Efficiency of secondary traits in selecting for improved grain yield in extra-early maize under Striga-infested and Striga-free environments. Plant Breeding 133:373-380.

Balestre M, Von Pinho R, Souza J, Oliveira R (2009) Genotypic stability and adaptability in tropical maize based on AMMI and GGE biplot analysis. Genet Mol Res. 8:13111322.

Barreiro-Hurle J (2012) Analysis of incentives and disincentives for maize in the United Republic of Tanzania. Technical notes series, MAFAP FAO, Rome

BMS (2015) The IBP Breeding Management System Version 3.0.8 CIMMYT, Mexico.

Bosque-Perez N, Olojede S, Buddenhagen I (1998) Effect of maize streak virus disease on the growth and yield of maize as influenced by varietal resistance levels and plant stage at time of challenge. Euphytica. 101:307-317.

Comstock R, Moll R (1963) Genotype-Environment Interactions: Stat Genet Plant Breed. NAS-NRC, Pubi.

Dehghani H, Sabaghnia N, Moghaddam M (2009) Interpretation of genotype-by-environment interaction for late maize hybrids' grain yield using a biplot method. Turk J Agric For. 33:139-148.

Farshadfar E, Rashidi M, Jowkar MM, Zali H (2013) GGE Biplot analysis of genotypex environment interaction in chickpea genotypes. Eur J Exp Biol. 3:417-423.

Gauch HG (2013) A simple protocol for AMMI analysis of yield trials. Crop Sci. 53:1860-1869.

Gethi J, Mukunya D, Githiri S, Nzuve F (2013) Combining abilities of maize inbred lines for grey leaf spot (GLS), grain yield and selected agronomic traits in Kenya. J Plant Breed Crop Sci. 5:41-47.

Hallauer AR, Carena MJ, Miranda Filho JD (2010) Quantitative Genetics in Maize Breeding, vol 6. Springer Science \& Business Media, USA.

Harismendy O, Ng PC, Strausberg RL, Wang X, Stockwell TB, Beeson KY, Schork NJ, Murray SS, Topol EJ, Levy S (2009) Evaluation of next generation sequencing platforms for population targeted sequencing studies. Genome Biol. 10:32-41.

Jandong E, Uguru M, Oyiga B (2011) Determination of yield stability of seven soybean (Glycine max) genotypes across diverse soil pH levels using GGE biplot analysis. J Appl Biosci. 43:2924-2941.

Kandus M, Almorza D, Boggio Ronceros R, Salerno J (2010) Statistical models for evaluating the genotypeenvironment interaction in maize (Zea mays L.). PhytonRevista Int de Bot Exp. 79:9-46.

Kota S, Singh S, Mohapatra T, Singh A, Bhadana V, Ravichandran S (2013) Genotypex environment interaction analysis for grain yield in new plant type (NPT) wheat derivatives. Sabrao J Breed Genet. 45:382-390.

Kyetere D, Ming R, McMullen M, Pratt R (1995) Monogenic tolerance to maize streak virus maps to the short arm of chromosome 1. Maize Genetics Cooperation Newsletter 69:136-136.

Lule D, Fetene M, de Villiers S, Tesfaye K (2014) Additive Main Effects and Multiplicative Interactions (AMMI) and genotype by environment interaction (GGE) biplot analyses aid selection of high yielding and adapted finger millet varieties. J Appl Biosci. 76:6291-6303.

Mesfin T, Bosque-Perez N, Buddehnagen I, Thottappilly G, Olojede $S$ (1992) Studies of maize streak virus isolates from grass and cereal hosts in Nigeria. Plant Dis. 76:789-795.

Mrutu BA, Feyissa T, Ndunguru J (2014) Assessment of genetic diversity of maize inbred lines and hybrids in Southern Highlands of Tanzania by using random amplified polymorphic DNA (RAPD) markers. Am J Res Commun. 2:84-99.

Mukherjee A, Mohapatra N, Bose L, Jambhulkar N, Nayak P (2013) Additive main effects and multiplicative interaction (AMMI) analysis of GXE interactions in rice-blast pathosystem to identify stable resistant genotypes. Afr J Agric Res. 8:5492-5507.

Munawar M, Hammad G, Shahbaz M (2013) Evaluation of maize (Zea mays L.) hybrids under different environments by GGE biplot analysis. Am-Eurasian J Agric Environ Sci. 13:1252-1257.

Negash AW, Mwambi H, Zewotir T, Taye G (2013) Additive main effects and multiplicative interactions model (AMMI) and genotype main effect and genotype by environment interaction (GGE) biplot analysis of multi-environmental wheat variety trials. Afr J Agric Res. 8:1033-1040. 
Nyoka B, Simons A, Akinnifesi F (2012) Genotypeenvironment interaction in Gliricidia sepium: Phenotypic stability of provenances for leaf biomass yield. Agric Ecosyst Environ. 157:87-93.

Oliveira RLd, Von Pinho RG, Balestre M, Ferreira DV (2010) Evaluation of maize hybrids and environmental stratification by the methods AMMI and GGE biplot. Crop Breed Appl Biot. 10:247-253.

Payne R (2014) A Guide To ANOVA and Design in GenStat. VSN International, Hemel Hempstead, Hertfordshire, UK.

Rad MN, Kadir MA, Rafii M, Jaafar HZ, Naghavi MR, Ahmadi F (2013) Genotype $x$ environment interaction by AMMI and GGE biplot analysis in three consecutive generations of wheat (Triticum aestivum) under normal and drought stress conditions. Aust J Crop Sci. 7:956-961.

Rashidi M, Farshadfar E, Jowkar MM (2013) AMMI analysis of phenotypic stability in chickpea genotypes over stress and non-stress environments. Int. J Agric Crop Sci. 5:253260.

SAS (2011) SAS/IML 9.3 User's Guide. SAS Institute Inc, Cary, NC, USA.

Snedecor GW, Cochran WG (1989) Statistical Methods, 8thEdn. lowa State Univ Press, Ames, lowa.
Tefera T, Mugo S, Beyene Y, Karaya H, Gakunga J, Demissie G (2013) Postharvest insect pest and foliar disease resistance and agronomic performance of new maize hybrids in East Africa. Int J Plant Breed Genet. 7: 92-104.

Trouche G, Bastianelli D, Hamadou TC, Chantereau J, Rami JF, Pot D (2014) Exploring the variability of a photoperiodinsensitive sorghum genetic panel for stem composition and related traits in temperate environments. Field Crops Res. 166:72-81.

Welz H, Schechert A, Pernet A, Pixley K, Geiger H (1998) A gene for resistance to the maize streak virus in the African CIMMYT maize inbred line CML202. Mol Breeding 4:147154.

Yan W, Kang MS, Ma B, Woods S, Cornelius PL (2007) GGE biplot vs. AMMI analysis of genotype-by-environment data. Crop Sci. 47:643-653.

Yan W, Tinker NA (2006) Biplot analysis of multienvironment trial data: Principles and applications. Can J Plant Sci. 86:623-645. 